\title{
Topographic Localization of Nerve to Masseter Muscle to determine the Primary Nerve- Muscle Relation, an Aid to Facial Sculpting Techniques
}

\author{
A. Ganapathy, V. Kumar, V. Prathapamchandra, JP Jessy, N. Rani, S. Kaler, S. Singh \\ Department of Anatomy, AlIMS, New Delhi, India
}

\author{
CORRESPONDING AUTHOR: \\ Seema Singh \\ Department of Anatomy, AllMS \\ New Delhi 110029, India \\ Tel: +91-9868943478 \\ E-mail: seemahkg@gmail.com
}

DOI:

10.32098/mltj.01.2020.17

LEVEL OF EVIDENCE: 1B

\begin{abstract}
SUMMARY
Background. The masseteric nerve is a suitable target as a motor nerve donor for facial reanimation surgeries and botulinum toxin injection in case of hypertrophy of masseter muscle. In this context determining the topographical location of the motor point (MP) of masseter muscle with reference to standard anatomical landmarks becomes significant.

Methods. Eleven formalin-fixed cadavers were dissected meticulously. After identifying the MP of the masseteric muscle, its distance from the preauricular point, the midpoint of the orbitomeatal line and angle of mouth were defined. The thickness of the masseter muscle was determined.

Results. The mean distance of the MP from the preauricular point, the midpoint of the orbitomeatal line and the angle of mouth were $5.59 \mathrm{~cm}, 3.43 \mathrm{~cm}$ and $5.14 \mathrm{~cm}$ respectively on the right and $5.11 \mathrm{~cm}, 3.32 \mathrm{~cm}$ and $5.36 \mathrm{~cm}$ respectively on the left side. The mean thickness of masseter muscle was $5.24 \mathrm{~cm}$ on right and $5.32 \mathrm{~cm}$ on the left side. Conclusions. The MP of masseter muscle lies at a point which is almost equidistant from the preauricular point and angle of mouth but in more proximity to the orbitomeatal line. Its entry into the masseter is on an average of $5.28 \mathrm{~cm}$ from the surface.
\end{abstract}

\section{KEY WORDS}

Cadaver; facial; motor point; neurotisation

\section{BACKGROUND}

Masseter muscle hypertrophy is an uncommon condition characterised by unilateral or bilateral fullness on the cheeks near the angle of the mandible. It is characterised by an increase in the mass of masseter muscle (1). Though usually asymptomatic severe cases can present with cosmetic disfiguration. It can result from emotional stress, chronic bruxism, masseteric hyperfunction and microtrauma (2). A hypertrophied masseter muscle will alter facial lines. This generates discomfort and has psychological effects on patients (1). The incidence for this condition is highest in the second and third decades of life. There is no specific gender propensity (3).

Treatment of masseter muscle hypertrophy ranges from pharmacotherapy to invasive surgical procedures like masseter muscle reduction, osteotomy and splint therapy. The primary purpose of the treatment is to give a positive aesthetic value. The procedures mentioned above do not satisfactorily give this. In this context, the injection of botulinum toxin type $\mathrm{A}$ is considered to be a less invasive and effective modality of treatment. It has been successfully used for cosmetic sculpting. It is a type of neurotoxin produced by clostridium botulinum. Its mechanism of action is to block the neuromuscular transmission by inhibiting the release of vesicle bound acetylcholine at the neuromuscular junction. This subsequently causes paralysis and atrophy of the muscle. In the case of masseter muscle hypertrophy, single injection technique involving the delivery of $40 \mathrm{U}$ of incobotulinumtoxin $\mathrm{A}$ is considered to be both safe and effective (4).

The technique of a successful botulinum injection depends on accurate localisation of the motor point of masseteric muscle. The motor point of a muscle is where a nerve enters a muscle which is relatively constant for a muscle. It is at the deep surface of the muscle near its least mobile attachment. This allows the muscle to move with minimum interference 
with the nerve trunk $(5,6)$. This is also important to avoid injury to nearby structures like parotid gland and the terminal branches of the facial nerve. Consideration of muscle depth is also crucial. Many studies are done on nerve muscle relations $(7,8)$ but that of the masseteric nerve are few. Also, these studies do not clearly mention the exact location of the nerve corresponding to masseter muscle in relation to standard surface anatomical landmarks (9).

Hence the present study aims to determine the precise topographical location of motor point of masseter muscle with reference to standard anatomical landmarks.

\section{MATERIAL AND METHODS}

The study meets the ethical standards of the journal (10). The study was conducted at the department of Anatomy AIIMS New Delhi between April 2019 and July 2019 on cadavers received by the department through voluntary body donation programme. Bilateral dissection of 11 formalin-fixed cadavers was done after recording their age, sex and cadaver number.

The masseter muscle was identified following the routine dissection procedure (11). The following surface anatomical landmarks were then marked, as shown in figure $\mathbf{1}$ :

1. preauricular point $(\mathrm{P})$;

2. orbitomeatal line (OML): from the lateral margin of the orbit to the preauricular point;

3. gonion line $(\mathrm{GL})$ : line from the midpoint of OML to the gonion (apex of maximum curvature on the angle of mandible);

4. angle of mouth (M).

The masseter muscle was carefully reflected from its attachment on the zygomatic arch. The reflection proceeded gradually from its medial to the lateral attachment. The mandibular notch was identified after reflecting the masseter muscle, and the masseteric nerve was identified. The motor point masseter muscle was identified. This point was marked on the external surface of the masseter muscle by inserting a probe. The muscle was then replaced to its anatomical location.

Then, the distance of the probe was measured from the following anatomical landmarks using vernier callipers up to 2 decimals:

1. preauricular point $(\mathrm{P})$;

2. midpoint of OML $(\mathrm{O})$;

3. angle of mouth $(\mathrm{M})$.

The thickness of the masseter muscle at the nerve entry point was noted as $\mathrm{T}$ using a vernier calliper and values were noted up to two decimal points (figure 1).
The location of the nerve entry point in front or at the back of the GL was noted.

\section{STATISTICAL ANALYSIS}

The normality of the variables was tested with the Shapiro-Wilk test / Kolmogorov Smirnov tests for normality. Mann-Whitney and unPaired t-test were carried out for comparison of Left and Right side. Spearman's and Pearson's correlation coefficient were used for comparing the above measurements with the right and left side. P value < 0.05 was considered significant. The analysis was conducted using IBM SPSS Statistics (version 22.0).

\section{RESULTS}

The mean, standard deviation and standard error of the mean of all the parameters are given in table $\mathbf{I}$. The mean length of the orbitomeatal line was $7.25 \mathrm{~cm}$ on right and $6.95 \mathrm{~cm}$ on the left side. The mean length of the line joining midpoint of the orbitomeatal line to gonion line (GL) was $7.21 \mathrm{~cm}$ on right and $6.76 \mathrm{~cm}$ on the left side. The motor point (MP) was observed in front of this line in all the cadavers except on the left side of one of them. Here the MP was behind the GL. The mean distance of the MP from the preauricular point $(\mathrm{P})$ was $5.59 \mathrm{~cm}$ on right and $5.11 \mathrm{~cm}$ on the left side. Its mean distance from the midpoint of the orbitomeatal line $(\mathrm{O})$ was $3.47 \mathrm{~cm}$ on right and $3.32 \mathrm{~cm}$ on the left side. From the angle of the mouth $(\mathrm{M})$, the mean distance of the MP was $5.14 \mathrm{~cm}$ on right and $5.36 \mathrm{~cm}$ on the left side. The mean thickness of masseter muscle $(\mathrm{T})$ was $5.24 \mathrm{~cm}$ on right and $5.32 \mathrm{~cm}$ on the left side.

The mean difference between the parameters on the right and the left side was analysed and is given in table I. No statistically significant difference was observed between the right and left side for the parameters mentioned above. The correlation coefficient was analysed between the side and the various measured parameters (table II). These differences were not statistically significant. The three most critical anatomical landmarks assessed were the preauricular point $(\mathrm{P})$, midpoint of $\mathrm{OML}(\mathrm{O})$ and angle of mouth $(\mathrm{M})$. Figure 2 gives the distribution of these parameters with respect to their distance from the MP of masseter muscle.

\section{DISCUSSION}

In the present study, we have seen the MP of masseter muscle from standard anatomical landmarks. These included the preauricular point $(\mathrm{P})$, angle of the mouth $(\mathrm{O})$ and the midpoint of the orbitomeatal line $(\mathrm{M})$. On an average the motor point of masseter muscle lies $5.35 \mathrm{~cm}$ from the 

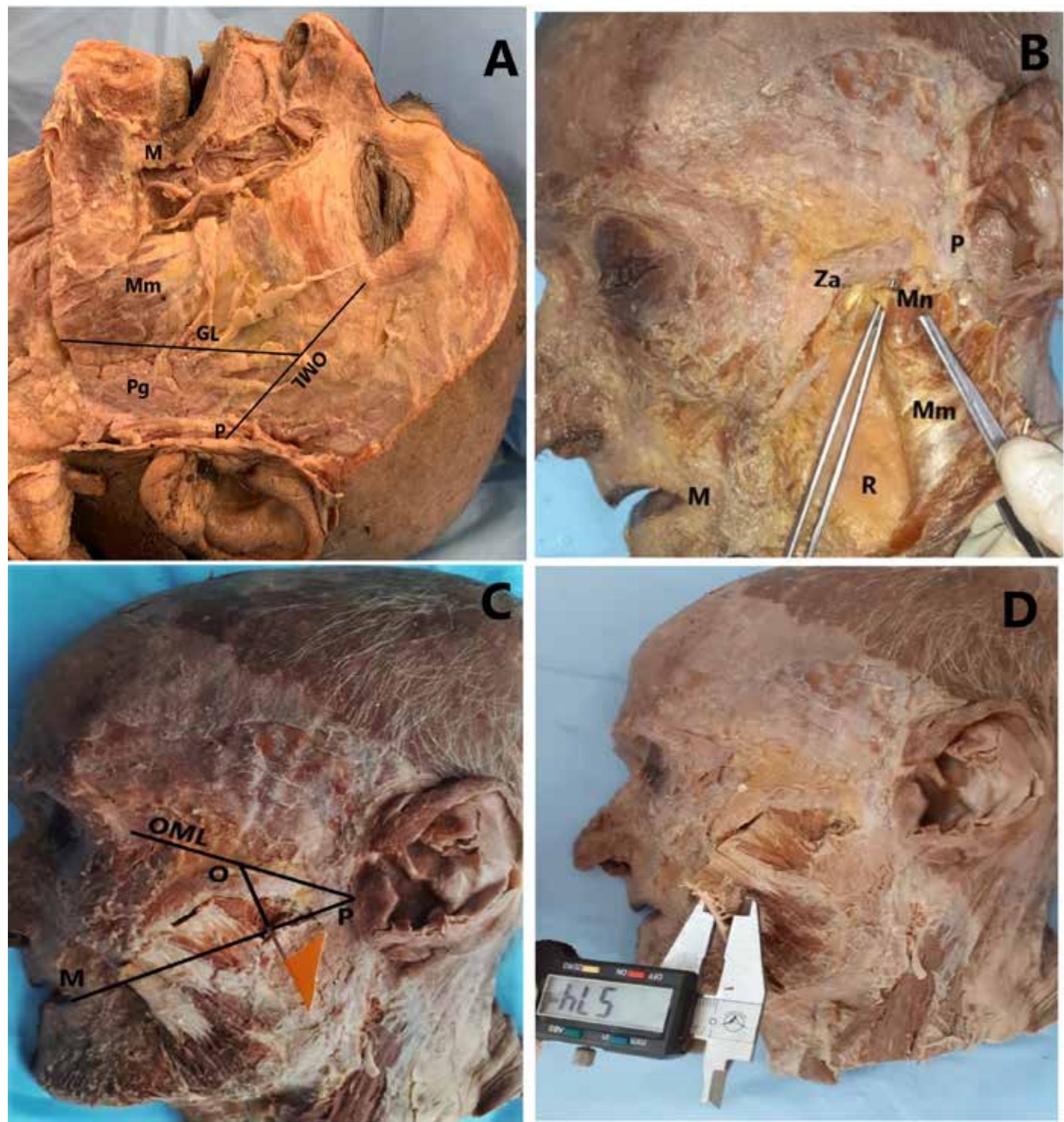

Figure 1. Photographs show the various anatomical landmarks and parameters in facial region of head and neck specimens. A. Shows anatomical landmarks- orbitomeatal line $(\mathrm{OML})$, preauricular point $(\mathrm{P})$, gonion line $(\mathrm{GL})$, angle of mouth $(\mathrm{M})$, masseter muscle $(\mathrm{Mm})$. B. Shows the motor point (MP) of masseter muscle. The forceps are just deep to the nerve. $\mathbf{C}$. The flag shows the MP from the surface of masseter muscle and the lines are the distances measured from the standard anatomical landmarks to the MP. $\mathrm{O}$ is midpoint of $\mathrm{OML}, \mathrm{P}$ is preauricular point, $\mathrm{M}$ is angle of mouth. $\mathrm{D}$. Measuring the thickness of masseter muscle with vernier callipers. Parotid gland (Pg); Ramus of mandible (R); Zygomatic arch (Za). 
Table I. Mean and standard deviation of various parameters measured.

\begin{tabular}{|c|c|c|c|c|c|}
\hline & SIDE & $\mathbf{N}$ & Mean (in cm) & Std. Deviation & $P$ value \\
\hline \multirow[t]{2}{*}{ OML } & RIGHT & 11 & 7.2545 & .76074 & .307 \\
\hline & LEFT & 11 & 6.9545 & .56633 & \\
\hline GL & LEFT & 11 & 6.7636 & .79658 & \\
\hline $\mathrm{P}$ & RIGHT & 11 & 5.5909 & .88708 & .249 \\
\hline $\mathrm{O}$ & LEFT & 11 & 3.3182 & .79097 & \\
\hline \multirow[t]{2}{*}{$\mathrm{T}$} & RIGHT & 11 & 5.2418 & 1.70845 & .911 \\
\hline & LEFT & 11 & 5.3182 & 1.43878 & \\
\hline $\mathrm{M}$ & RIGHT & 11 & 5.1364 & 0.36680 & 0.613 \\
\hline
\end{tabular}

OML: Orbito Meatal Line, GL: Gonion Line, P: distance of motor point of master muscle from Pre auricular point, O: distance of motor point of master muscle from midpoint of orbitomeatal line, T: Thickness of masseter muscle, M: distance of motor point of master muscle from angle of Mouth.

Table II. Correlation of side with the various parameters.

\begin{tabular}{ccc}
\hline Parameters & Correlation coefficient & P value \\
\hline OML & -.228 & .307 \\
\hline GL & -.285 & 0.198 \\
\hline $\mathrm{P}$ & -.257 & .249 \\
\hline $\mathrm{O}$ & -.109 & .631 \\
\hline $\mathrm{T}$ & 0.025 & .911 \\
\hline $\mathrm{M}$ & 0.110 & 0.625 \\
\hline
\end{tabular}

OML: Orbito Meatal Line, GL: Gonion Line, P: distance of motor point of master muscle from Pre auricular point, O: distance of motor point of master muscle from midpoint of orbitomeatal line, T: Thickness of masseter muscle, M: distance of motor point of master muscle from angle of Mouth.
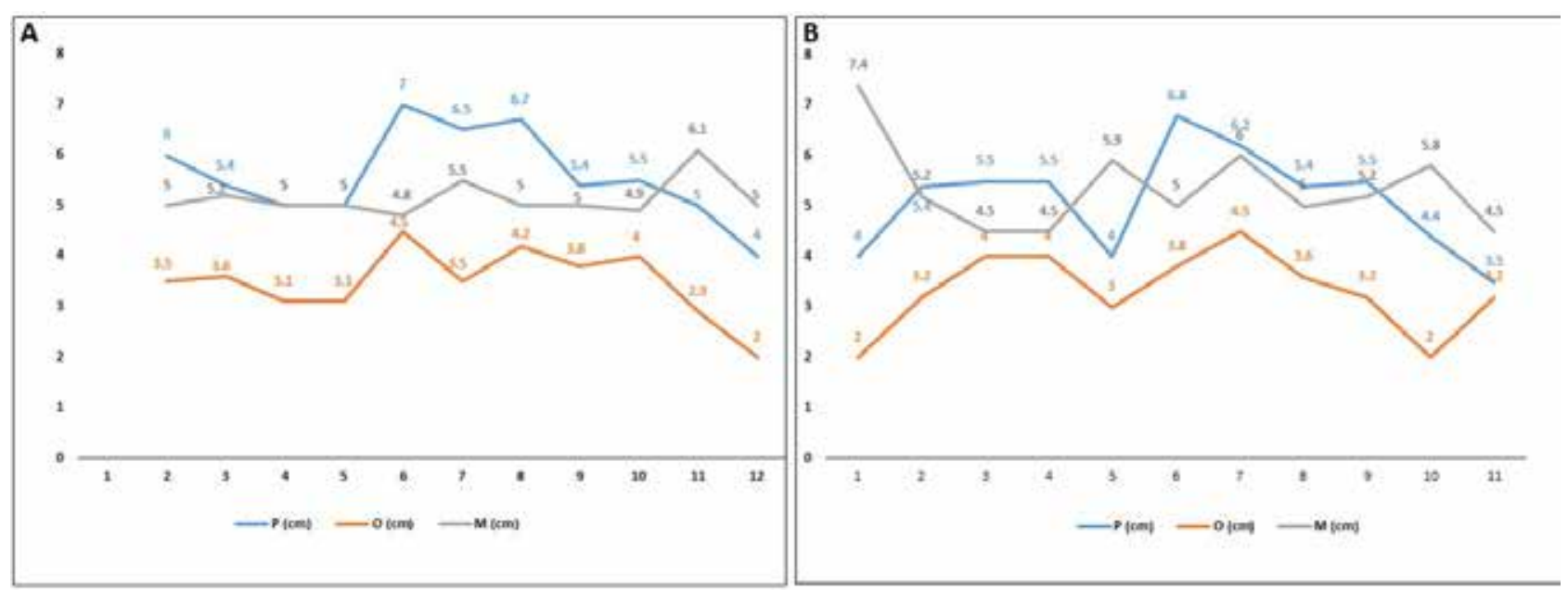

Figure 2. Graph shows the distribution of parameters with respect to their distance from the motor point of the masseter muscle. A. Right side, B. Left side. P: Distance from the preauricular point, O: Distance from midpoint of orbitomeatal line, M: Distance from the angle of mouth. The Motor Point lies almost at an equal distance from the pre auricular point and the angle of mouth but closer to midpoint of OML. 
preauricular point, $3.40 \mathrm{~cm}$ from the midpoint of orbitomeatal line and $5.25 \mathrm{~cm}$ from the angle of mouth. The mean thickness of masseter muscle at the MP was $5.24 \mathrm{~cm}$ on right and $5.32 \mathrm{~cm}$ on the left side.

The point of entry of the masseteric nerve into the masseter muscle lies in a very accessible point which is almost equidistant from the preauricular point and angle of mouth but in more proximity to the midpoint of orbitomeatal line. Its entry into the masseter is on an average of $5.28 \mathrm{~cm}$ from the surface. This topographical analysis gives a very precise location of the motor point. Though the values we measured were precise but were not statistically significant. This could be accounted to the less number of specimens used.

The role of the nerve to masseter muscle in facial rehabilitation was first described by Spira M., 1978 (12). The masseteric nerve is currently being opted for nerve grafting in case of facial reanimation surgeries. The main aim of the reconstruction procedures is to attain facial symmetry and functional rehabilitation. Use of masseteric nerve has an advantage over the standard procedure of nerve grafting using the hypoglossal nerve as hypoglossal-facial anastomosis causes partial atrophy of the tongue (13). Previous studies have also shown that there is a fast recovery with minimal morbidity when the masseteric nerve is used for facial nerve reconstruction (14). In this context it is very important to know the course of masseteric nerve and also its point of entry into the masseter muscle. Murphy et al., 2018 (15) in their systemic review and meta-analysis done in 2018 have reported that compared with other direct nerve anastomoses, there is considerably less published literature reporting outcomes with masse-

\section{REFERENCES:}

1. Biruktawit Kebede, Shimalis Megersa. Idiopathic Masseter Muscle Hypertrophy. Ethiop J Health Sci 2011; 21(3): 209-212.

2. M. Ayhan, Sabri Cemil İşler, C. Kasapoglu. Combination of Medical and Surgical Treatments for Masseter Hypertrophy. Case Reports in Dentistry 2018; 1-6.

3. Naresh Shetty, Rajanikanth K. Malaviya and M. K. Gupta. Management of Unilateral Masseter Hypertrophy and Hypertrophic Scar-A Case Report. Case Reports in Dentistry 2012; 1-6.

4. Andreas Nikolis, Kaitlyn M Enright,Sofia Masouri, Steven Bernstein, Christina Antoniou. Prospective evaluation of incobotulinumtoxin $\mathrm{A}$ in the management of the masseter using two different injection techniques. Clin Cosmet Investig Dermatol 2018; 11: 347-356.

5. Standring, S.Gray's Anatomy, The anatomical basis of clinical practice. 41st ed. Elsevier Churchill Livingstone; London, 2016; p.107.

6. Snell RS. Clinical Anatomy by regions. 9th ed. Lippincott Williams and Wilkins; Baltimore, 2008; p. 9. ter to facial nerve coaptation. This brings us to the significance of the present study.

Cotrufo et al., 2011 (16) have identified the emergence of the masseter nerve at the mandibular notch and its distance from the zygomatic arch for the purpose of using it for facial reanimation surgeries. For the procedure of neurotisation, it is essential to describe the site of nerve entry that is the motor point of the muscle from standard anatomical landmarks. Kaya et al. (9) have described the motor nerve entry point in front or behind the line joining the angle of the mandible to the midpoint of a line extending from the lateral palpebral fissure to tragus. However, this alone is not enough to describe the exact topographic location of the nerve entry point. Also, the thickness of masseter muscle plays a significant role at localisation of motor point as it varies between the individuals. This was not described in previous studies. In the present study we have described the topographic location of motor point of masseter muscle with reference to an accurate and unique triangle formed by three standard anatomical landmarks (midpoint of orbitomeatal line, angle of mouth and preauricular point) which was not described in past literature $(9,16)$. These three osteal anatomical landmarks can be effortlessly identified, thereby facilitating various surgical procedures.

Future studies could be targeted at the relation of masseteric nerve to branches of facial nerve to assess the accessibility of nerve used and also to evaluate which technique will provide the best outcomes.

\section{CONFLICT OF INTERESTS}

The authors declare they have no conflict of interests.

7. Shengbo Yang, Shuaiyu Hu, Bangguo Li, Xiaomei Li. Localisation of nerve entry point and intramuscular nerve-dense regions as targets to block brachioradialis muscle spasticity. Int J Clin Exp Med 2017; 10(8):11912-20.

8. Safwat MD, Abdel-Meguid EM. Distribution of terminal nerve entry points to the flexor and extensor groups of forearm muscles: an anatomical study. Folia Morphol (Warsz) 2007; 66(2):83-93.

9. Kaya B, Apaydin N, Loukas M, Tubbs RS. The topographic anatomy of the masseteric nerve: A cadaveric study with an emphasis on the effective zone of botulinum toxin A injections in masseter. J Plast Reconstr Aesthet Surg 2014; 67(12):1663-8.

10. Padulo J., Oliva F., Frizziero A., Maffulli N. Muscles, Ligaments and Tendons Journal - Basic principles and recommendations in clinical and field Science Research: 2016 Update. MLTJ 2016; 6(1): 1 - 5 .

11. Rachel Koshi. Cunningham,s Manual of Practical Anatomy, Volume 3 Head, neck, and brain. 16th Ed. Oxford university press; 2018. 181-5. 
12. Spira M. Anastomosis of masseteric nerve to lower division of facial nerve for correction of lower facial paralysis. Preliminary report. Plast Reconstr Surg 1978; 61(3):330-334.

13. Bermudez LE, Nieto LE. Masseteric-facial nerve anastomosis: case report. J Reconstr Microsurg 2004; 20(1):25-30.

14. Brenner E, Schoeller T. Masseteric nerve: a possible donor for facial nerve anastomosis? Clin Anat.1998; 11(6):396-400.
15. Alexander W. Murphey, William B. Clinkscales, Samuel L. Oyer. Masseteric Nerve Transfer for Facial Nerve Paralysis A Systematic Review and Meta-analysis. JAMA Facial Plast Surg. 2018; 20(2): 104-110.

16. Cotrufo S, Hart A, Payne AP, Sjogren A, Lorenzo A, Morley S. Topographic anatomy of the nerve to masseter: an anatomical and clinical study. J Plast Reconstr Aesthet Surg.2011; 64(11):1424-9. 